\title{
Microscopy characterization of metallurgical production evidences from Vila Nova de São Pedro (Azambuja, Portugal)
}

\author{
F. Pereira****, R. J. Silva**, A.M. Monge Soares****** and M.F. Araújo**
}

*CENIMAT/I3N, Departamento de Ciências dos Materiais, Faculdade de Ciências e Tecnologia da Universidade Nova de Lisboa, 2829-516 Monte de Caparica, Portugal

**IST/ITN, Instituto Superior Técnico, Universidade Técnica de Lisboa, Estrada Nacional 10, 2686-953

Sacavém, Portugal

***Museu Arqueológico do Carmo, Associação dos Arqueólogos Portugueses, Largo do Carmo, 1200-092

Lisboa, Portugal

The Castro de Vila Nova de São Pedro (VNSP) is an emblematic settlement located at Azambuja (Portugal), occupied predominantly during the Chalcolithic period [1]. A large and diversified metallurgical collection was recovered from this settlement which includes artefacts, crucibles and other metallurgical production remains, like slags and droplets [1]. The chemical and microstructural characterization of this metallic collection aims to contribute to a better comprehension of the early copper-based metallurgy on the Portuguese Estremadura, the degree of knowledge of the ancient metallurgists and the role of the metallurgical activities in Chalcolithic societies.

A group of 53 selected copper-based fragments of artefacts plus metallurgical production remains (12 crucibles and 20 slags and droplets), all belonging to VNSP, were characterized by using different analytical techniques: EDXRF and micro-EDXRF spectrometry, optical microscopy (OM) and SEM-EDS. The EDXRF and microEDXRF spectrometry gives the elemental composition of the artefacts and metallic nodules. The microscopy techniques play a fundamental role in the chemical and microstructural characterization of artefacts and metallurgical remains. The OM allows the identification of different phases, inclusions and thermomechanical processes applied during the shaping of the artefacts. The SEM-EDS plays an important role in the determination of main chemical phases present in the metal alloy and slags, and also in the distribution of chemical elements and minerals in the inclusions. The combination of these two microscopy techniques gives indication of the processes used in the reduction of minerals in order to obtain the metal and also allows the characterization of the operation chain, regarding the production of artefacts.

The research that has been carried out by us offer indications concerning the provenance of the arsenic, the technological choices involved in the production of an arsenical copper alloy and how it was recognized by ancient metallurgists. Results obtained on the elemental composition of the metallurgical production remains are consistent with copper and arsenical copper (As $>2 \%$ ) artefact production [2]. Crucibles and slags analysed indicate melting and smelting operations (of copper ores or copper/arsenic ores). A statistically significant association was found between copper alloyed with arsenic and artefacts classified as tools/weapons (arrowheads, daggers and knives). In several cases, the presence of arsenic rich phases in the microstructure, resulting from an inverse segregation phenomenon, shows no evidence of chemical homogeneity control during the artefact manufacture [2]. Microstructural analyses also show that the majority of the artefactual group was shaped with forging plus annealing operation cycles and $23 \%$ of the artefacts received a final forging treatment. This final treatment was associated to artefacts presenting higher arsenic contents [2].

\section{References}

1. Arnaud J.M. and Fernandes C.V., Construindo a memória. As colecções do Museu Arqueológico do Carmo. In: eds. 140-188, 2005.

2. Pereira F., Archaeometallurgical Study of Artefacts from Castro de Vila Nova de São Pedro (Azambuja, Portugal). MSc Thesis, FCT-UNL, 2011. 

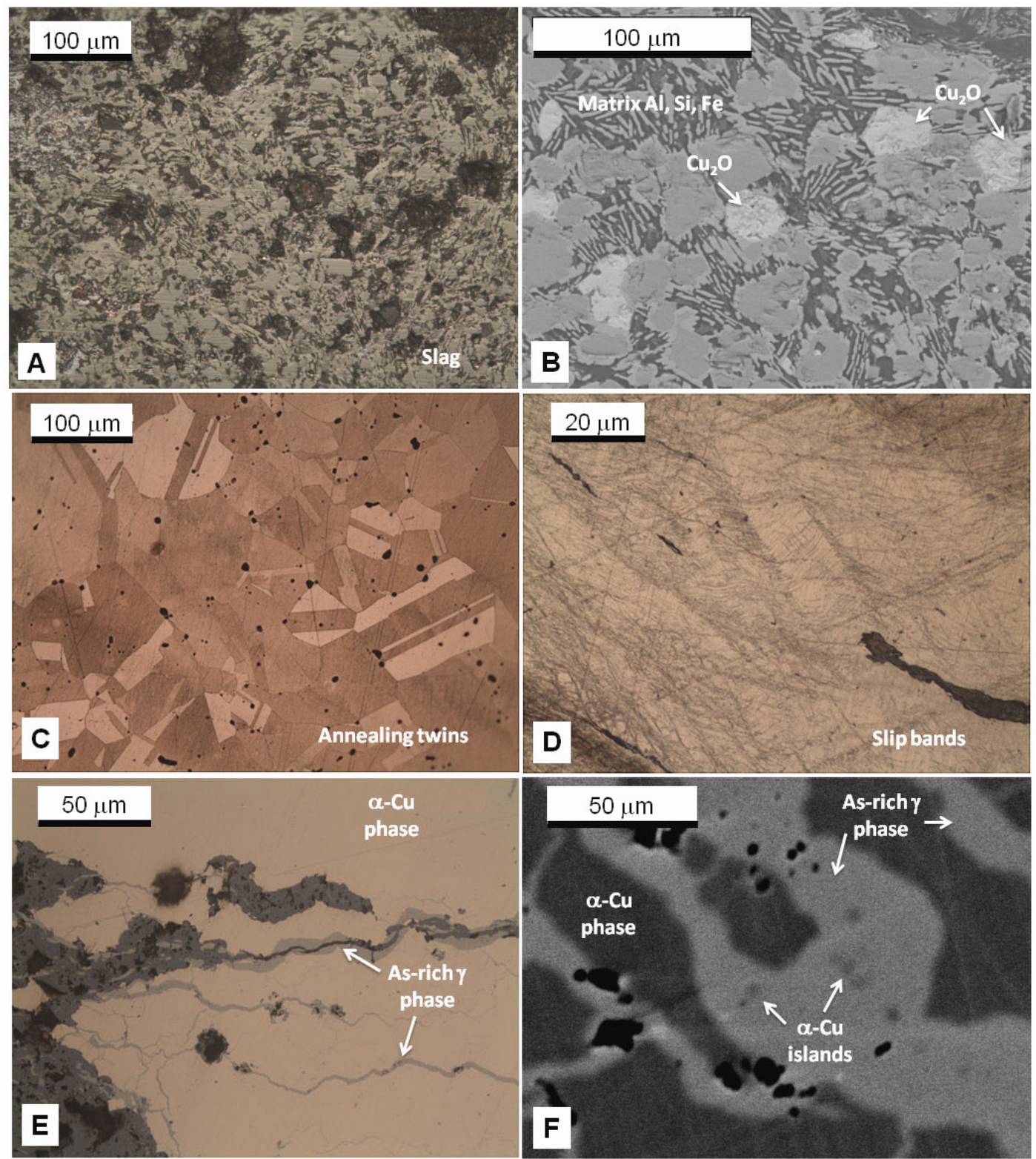

Figure 1. A: OM image of the slag VNSP280 (BF illumination); B: SEM-BSE image of the slag VNSP280 that allowed the characterization of a Si, $\mathrm{Ca}, \mathrm{K}, \mathrm{P}$ and Fe rich matrix and oxidized $\mathrm{Cu}$ globules; $\mathrm{C}$ : OM image of the chisel VNSP137C (As $<0.10 \%$ ) revealing annealing twins (BF illumination, etched); D: OM image of the awl VNSP025A ( $\mathrm{As}=3.37 \%$ ) revealing slip bands (BF illumination, etched); E: OM image of the awl VNSP097A $(\mathrm{As}=6.04 \%)$ revealing the grey arsenic-rich $\gamma$ phase (BF illumination); F: SEM-BSE image of the axe VNSP148D (As $=9.13 \%)$ that allowed the characterization of the arsenic-rich $\gamma$ phase, $\alpha$-Cu phase and $\alpha-\mathrm{Cu}$ islands.

This research work has been financed by the Portuguese Science Foundation (FCT-MCTES) through the EarlyMetal project (PTDC/HIS-ARQ/110442/2008) and the PhD Grant SFRH/BD/78107/2011 (FP). The financial support of CENIMAT/I3N through the Strategic Project-LA25-2011-2012 (PEstC/CTM/LA0025/2011) is also acknowledged. 